\title{
Investigational Product and Clinical Trial Supplies Filenote
}

National Cancer Institute

\section{Source}

National Cancer Institute. Investigational Product and Clinical Trial Supplies Filenote. NCI

Thesaurus. Code C115506.

A notation pertaining to the investigational product, and associated trial supplies used in a clinical trial. 